\title{
Crucial Factors that Affect Vietnamese Undergraduate Students' Motivation in Learning English as a Foreign Language
}

\author{
Doan Thi Hue Dung \\ Department of English Language, Hong Bang International University, Ho Chi Minh City 700000, Vietnam
}

Received September 27, 2020; Revised December 1, 2020; Accepted December 6, 2020

Cite This Paper in the following Citation Styles

(a): [1] Doan Thi Hue Dung "Crucial Factors that Affect Vietnamese Undergraduate Students' Motivation in Learning English as a Foreign Language," Universal Journal of Educational Research, Vol. 8, No. 12B, pp. 8068-8074, 2020. DOI: 10.13189/ujer.2020.082608.

(b): Doan Thi Hue Dung (2020). Crucial Factors that Affect Vietnamese Undergraduate Students' Motivation in Learning English as a Foreign Language. Universal Journal of Educational Research, 8(12B), 8068-8074. DOI: 10.13189/ujer.2020.082608.

Copyright $\mathrm{C} 2020$ by authors, all rights reserved. Authors agree that this article remains permanently open access under the terms of the Creative Commons Attribution License 4.0 International License

\begin{abstract}
The paper aims to address the significant factors that affect the motivation to acquire English language skills of Vietnamese undergraduate students. This descriptive research study is mainly based on the survey using both questionnaires and interviews, conducted with 288 students at the Department of English Language of Hong Bang International University in Ho Chi Minh City. The findings show that both intrinsic and extrinsic factors play obvious impacts on the student's learning motivation, behavior, and performance. The major extrinsic factors include the teacher's role, the course atmosphere, the learning environment, the expectations from students' parents, the rates of incomes revealed in the job market, and the socio-educational environment. The intrinsic factors mainly include student's language competency, student's type of personality, and personal interests. Based on the findings of the study, the paper also proposes necessary implications to enhance the students' motivation of learning, aiming for increasing their success in the study program. In theoretical aspects, the study highlights the role of culture in shaping the student's motivation of learning. The study also attempts to differentiate types of learning motivation in terms of their time span, such as short-term, long-term, and lifelong motivation.
\end{abstract}

Keywords Student Motivation, English Language Skill, Vietnamese Higher Education, English Learning

\section{Introduction}

English language competence is a mandatory indicator of learning outcomes required at all levels in the Vietnamese educational system, from elementary to post-graduate education. English is also widely used in education, business, and many areas of the socio-economic life of the country. Together with the moving forwards to globalization and international integration direction, the job markets continuingly demand the graduates with high level of English language skills. Though Vietnam has introduced a comprehensive policy on the English language education since the year 2000, emphasizing the significant role of English as key instrument for education and business growth, the English teaching and learning at undergraduate level, in particular, still have many shortcomings and need more timely and effective measures. The yearly rate of drop out among English majored students at most universities is above $15 \%$. It is even more alarming that only $5 \%$ graduates gain confidence to use English at work and less than 15\% graduates can use English effectively at their workplace. These indicators were clearly reported at the conference on "new trends of teaching and learning foreign languages in the 4th industrial revolution" held by the National 
University of Ho Chi Minh City on 15 December 2018 [1].

There have been tremendous changes in the English teaching and learning domain in Vietnam in recent years, marked by the increase in the quality of academics, the fast application of digital technology, and the growing demand of using English in all sectors of the economy. However, it is a critical issue that achievement in learning English at university level does not keep pace with these positive changes. This study attempts to look at the student's motivation as a potential determinant for improvement of the student's English learning achievement. In other words, the motivation of acquiring English language skills is viewed as the most critical element that impacts the quality of teaching and learning English at the university level.

As Brown [2] points out, learning English is a lot more engaging when one is motivated. The overall objective of the study is to analyze the factors affecting the motivation to learn English language of undergraduate students at Hong Bang International University in Vietnam, and to make suggestions to enhance the achievement in teaching and learning at the regarded institution. In effect, the study aims to answer the following research questions:

1. What motivate the Vietnamese undergraduate students to learn English language?

2. What are the crucial factors that affect the students' motivations to learn English language skills?

\section{Materials and Methods}

\subsection{Definitions of Motivation}

There are not many precise definitions of motivation due to its dynamic and complicated nature. Motivation, or human motivation, is a complex concept in terms of structure, classification, or even hierarchical organization of motives. Motivation differs from person to person, and even from time to time for the same person. What motivates oneself may not have the same effects to another person, and what motivates that person today will be most likely not on the same degree of motivating anymore for that person in the future $[2,3]$. Similarly, Harmer [4] also sees motivation as a kind of impulse, or internal drive that stimulates a person to perform a course of actions, which are either situational or task-oriented. Many psychologists see motivation as the composing of need, action, and goal. In the educational area, motivation never operates in isolation because motivation, learning, and perception are in a constant state of interaction, each affecting and being affected by the other two [5]. In general, motivation is a kind of internal and external drive that stimulates a person to perform a course of intended actions.

\subsection{Motivation for Learning and the Role of Teachers}

Simply, motivation for learning is wanting and needing to learn [6]. In other words, motivation in learning is the desire by which students are affected to participate in the process of learning. In the real life of teaching, to understand the learner's actual motivation of learning is one of the biggest challenges for the teacher. The teacher can only collect the learners' perception, observe their behaviors, and judge their performance in the learning process.

Furthermore, motivation closely associates to emotion, and makes impacts on the learner's behavior and performance in learning. Brown [2] even sees motivation in learning as a kind of competence which can be obtained through experience accumulating. In this process, the learner is stimulated almost directly from modeling, direct instruction, socialization and communication with their course mates, teachers, and family members.

Motivation is, therefore, widely seen as one of the vital factors that decide students' retention and learning efficiency [7]. Sundqvist [6] also notes that sometimes students are at a loss and do not know what to do or why they take English as a major at the first place. Therefore, with the understanding of the student's motivation of learning, the teacher can make better adjustments and provide more appropriate instruction and counselling during the course.

Similarly, Brew and Burgess [8] note that it is important for teachers to motivate their students because student motivation correlates with a student's academic achievement. It is also important to explore what intrinsically motivates college students to continue attending class. Brew and Burgess also find out that college teachers' classroom performance can influence the students' motivation to attend class. In addition, specific teaching methods, personal qualities, and classroom management practices were identified as motivating or unmotivating factors [8].

\subsection{Types of Motivation}

Motivation can be generally classified into two smaller categories: intrinsic and extrinsic motivation [9]. Intrinsic motivation describes an internal source which can urge one forward in action, including an inner purpose and sense of accomplishment that can enhance self-esteem as well as performance in the classroom. Students' behaviors in learning are driven by internal rewards [9].

Students who are intrinsically motivated actively engage in classroom activities without outer interferences of any kind. They find the materials and the lessons naturally interesting, and therefore, are willing to participate in the learning process voluntarily. It is supposed that curiosity and the sense of achievement thirst are what drive students with intrinsic motivation. In other words, they do not necessarily require a reward or any 
incentive to learn [10].

On the other hand, extrinsic motivation is an external source which fosters or encourages an individual to succeed. It mainly concerns outer factors in the classroom. Extrinsic sources can be different objects, people, phenomena, and can be taken literally and figuratively. It can come under the shape of a family member, or the teacher who is in charge. It also involves the system of reward and punishment. A student can be identified as extrinsically motivated when they take part in the learning process to obtain a reward or to avoid getting some undesired punishment [5].

More specifically, Mitchell and Myles [11] highlight that social context leads to attitudes of various kinds which appear in the learner as motivation. In other words, the socio-educational environment forms the vial source of extrinsic motivation among students.

This study attempts to classify factors affecting the student's motivation into intrinsic and extrinsic types. The intrinsic factors include personal interests, personal learning experiences, English competence, and personal social skills, etc. The extrinsic factors come from peers, teachers, parents' involvement, learning environment, and socio-educational environment.

In this fast-changing world, it is also necessary to examine the student's motivation in terms of its time span such as short-term, long-term, and life-long. Lifelong motivation might come in line with lifelong goals. It is the desire to fulfil a lifelong plan or a lifelong goal. In certain cases, even when a person changes his lifelong goal, his lifelong motivation might still have effect. However, if lifelong motivation is interrupted or changed, the lifelong goal is unlikely to be obtained. The motivation to become a great teacher, a successful manager, or a known news anchor, etc. is a common kind of motivation that an English majored student might carry throughout his life.

Long-term motivation, on the other hand, helps a person to complete a long-term project or an important goal. Long-term motivation might or might not go along with a person's lifelong motivation. In the reality, many people might change their study programs or even change their jobs in order to pursue their lifelong goals and motivation. The motivation to complete an undergraduate program is seen as a long-term one. Without maintaining this years-long motivation, the student cannot complete the course requirements, and then cannot graduate from the degree programs.

On the road to fulfil the long-term goal, a student might be distracted with several immediate and short-term interests, passion, and plans, which are carried out with short-term motivations. In this study, the motivation to acquire English language skills is viewed as a long-term motivation. It should normally stay with the students for at least three or four years while taking their undergraduate programs. In fact, staying highly motivated to learn English language while having many short-term motivations for many non-academic activities is a real challenge for most undergraduate students.

\subsection{Motivation in a Learning Spectrum}

Motivation is viewed as a vital chain in the spectrum of perception - motivation - learning performance - learning achievement (Figure 1). Perception relates to the awareness, attitude, emotion, need, and goal. In Vietnamese perspectives, learning a foreign language makes a person likely different from other fellows because that person is one step closer to the outside world. It is also a common perception that foreign language makes a person more open, sociable, confident, advanced, independent, and dynamic. These characteristics are more seen in Western cultures than in Vietnamese culture. Without these traits of personality, the student feels hesitating to take English language major. In other words, culture has some impact on the perception of a person on learning English.

A relevant study also finds out that in today's interconnected multicultural world the levels of students' intercultural communicative competence play an important role in the amount of enthusiasm, time, and efforts they invest in second or foreign language communication and learning. There was a strong, positive relationship between the student's intercultural communicative competence and his learning motivation [12].

In brief, perceptions about education, future work, and the society also influence the student's motivation of learning, learning performance, and learning achievement. In return, learning achievement in term of knowledge gained and competence acquired will likely affect a person's perception.
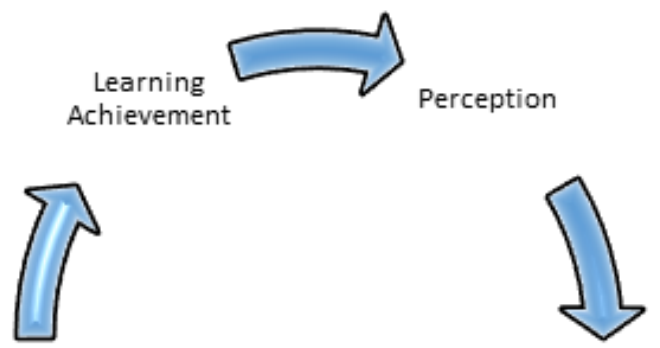

Learning

Performance

Motivation

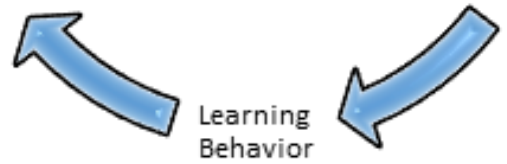

Figure 1. Motivation in the spectrum of learning

\subsection{Recent Studies on Vietnamese Undergraduate Students' Motivation of Learning}

There are some studies previously dealing with 
Vietnamese learners' motivation to learn English. These studies mainly focus on non-formal forms of learning or deal with a specific English skill $[13,14]$. In their study, Truong and Archer discuss the predominant motivation of undergraduate students taking English courses as a means of pleasing parents and bringing honor to their family. Using expectancy-value model theory, the study finds out that students' expectancy to do well in English predicts students' achievement in English. Family's expectation on the benefit of learning English also predicts the students' interest in English and willingness to learn English [14]. This finding aligns with the Vietnamese cultural contexts, where parents have rather strong influence on the student's decision in choosing majors and courses to study. Tran [13], from another angle, sees the significance of student's cognitive need or intrinsic motivation in driving the student's learning performance and achievement. Students show their potential to write independently, creatively, and passionately if they are autonomous and motivated. It is important to notice the multifaceted influence of cultures on the motivation of learning. Not only the socio-educational environment that defines the motivation of the student, cultures have the place in both intrinsic and extrinsic motivation of a person.

\section{Research Design}

This research employed a mixed method of data collection, based on both qualitative and quantitative sources. The questionnaires were conducted with 288 undergraduate students, followed by the interviews with 36 randomly selected students in the Department of English Languages of Hong Bang International University during the first semester of the academic year 2019-2020, from September to December 2019. The questionnaires were sent to the total population of 305 English majored students of the Department and 288 were returned. As for the unstructured interviews, the participations were randomly selected from all 9 classes based on the lists of students. 4 students on each list were chosen and invited for the interviews with the researcher.

The aims of the survey are to collect the participants' perspectives on the role of English language learning and to identify various types of motivation of learning. The interviews are unstructured and last from 15 to 30 minutes each, aiming to investigate the intrinsic and extrinsic factors affecting the students' learning behaviors and performance during their course of study. Since motivation for learning is highly personal, individual, and closely associated with emotion and perception, the use of interviews in this study contributes an appropriate form of data collection.

At the research site, the Department of English Language has in total 305 English majored students and 16 lecturers. All lecturers hold postgraduate degrees from overseas universities, of whom 4 are international nationals. The Department offers the undergraduate programs in English Language major which consists of 3 main components: English language skills, core courses of linguistics, cultures and literature; and specialized courses linking to the future profession in teaching English, office work, and business management. This study limits its scope to the English language skill component. The expected outcomes of English proficiency of the students on graduation are equivalent to the IELTS 6.0 or C1 level of the Common European Framework of Reference for Languages (CEFR). In order for the students to reach this goal, they undertake a variety of courses for English skills and knowledge including Speaking, Listening, Reading, Writing, Grammar, and Pronunciation. These foundation courses prepare the students with adequate English competence to study more advanced and specialized courses in the later stages of their study such as linguistics, literature, cultural studies, TESOL methodology, and business management. The rate of drop out from the foundation to the core stage is as high as $25 \%$ yearly. It is indeed a warning indicator for the student and the institution alike.

\section{Findings and Discussions}

\subsection{Indications of Motivation in Learning English}

The questionnaire and interview questions explore the respondents' motivational behavior and performance in learning. The indicators include the time spent for practicing English outside class, attendance manner, use of learning resources, and extra-curriculum activities that the respondents take part in. The questions mainly asked the frequency of these activities. The interviews also focus on the respondents' learning performance including levels of participation in the lesson, the completion of homework and coursework, and the attitude towards groupwork and projects.

\subsubsection{How often do the students practice English skills outside class?}

Practicing English outside class is viewed as the behavior driven mainly by intrinsic motivation. The more frequently the practice takes place, the stronger motivation for learning English is indicated. The following chart describes the frequency that the participants practice their English language skills outside the classrooms. It is worth mentioning that only $35.7 \%$ (103 participants) of the students practice their English skills including speaking, listening, reading, and writing on an everyday basic. The rate is unexpectedly low for English majored students. The numbers of participants who practice three times and two times a week are also low (73 and 68 students), making $25.3 \%$ and $23.6 \%$ respectively. 


\subsubsection{What resources do the students use to practice their} language skills?

Figure 3 summarizes the most common resources that the students use to practice their speaking and listening skills. The indicators show the numbers of students in each common type of resources. It is alarming that the numbers of students who make use of supplementary resources for the purpose of practicing English skills are rather limited. English songs are the most popular type being used (226 students). Other useful sources of English language such as movies (96 students), YouTube clips (80 students), news on TV (60 students), books (55 students), and digital games and apps (52 students) are not regularly used for self-practicing English skills. The interviews discover that the participants do not have enough time for practicing their English skills outside class. In other words, time for self-studying and self-practicing English language skills is inadequate. It is because the students have a tight schedule of studying on campus.

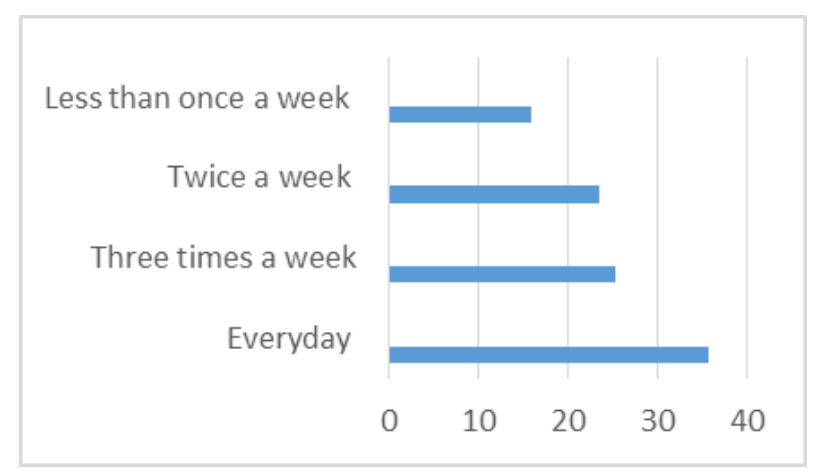

Figure 2. The frequency of practicing English language skills outside class

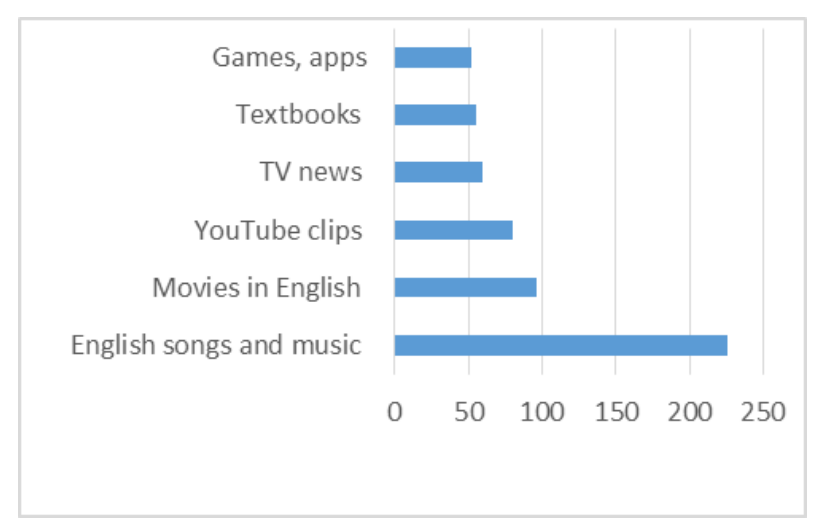

Figure 3. Resources used for practicing English language skills

\subsubsection{Learning performance}

Attendance manner of the student is the first indicator that needs mentioning. Without attendance regulations put in place, whether or not the students come to class regularly is normally the deep concern on the part of the teacher. Around $60 \%$ of the interviewed respondents said they would attend classes even though the teacher did not impose attendance requirements. In other words, around
$40 \%$ of the students did not enjoy attending all classes. The main reasons came from personal motives. For examples, the respondents shared their reluctancy to attend classes from 7AM while afternoon classes are preferable. The majority of the students could not give specific reasons for their preference to be absent from classes. It seemed a common trend that most students like to experience cutting classes once a while, as being a student. It gives students a sense of personal freedom.

$100 \%$ interviewed respondents revealed that their interests in learning were strongly affected by the teacher. The teacher's enthusiasm in working with students and the friendly, lively atmosphere that the teacher brings to the classrooms is highly appreciated. This is one of the common remarks:

"I like the subject because Teacher $\mathrm{O}$ is very kind, enthusiastic and caring for students' needs and progress. He made us interested in the lessons. I like to attend his class and participate well in the lesson. I completed all the assignment he gave us."

In other cases, students do not find enough interest and motivation to study certain subject or course due to the lack of attention given to students by the teacher in charge:

"I did not learn much from the course. In fact, I did not know exactly what the course was about. Teacher Q did not pay enough attention to how we coped with the course. After a few weeks of attending the course, I gave up and waited to repeat the course."

\subsubsection{Students' participation in extra-curriculum activities}

$67 \%$ (192 students) of the questionnaire participants show their appreciation of taking part in student activities such as English contests, English festivals, and community work. These activities give them the good opportunity for social interaction, team building practice, and more importantly for improving their English communicative skills. $100 \%$ interviewed participants remark the importance of student activities in helping student to develop their English language skills. However, only about $40 \%$ respondents actually took part in those activities. The reasons for not actively joining these group activities are being lack of confidence, lack of time, lack of English communicative ability.

\subsection{Major Motivations to Learn English Language}

The questionnaire survey finds that intrinsic motivation is more significant than the extrinsic one, which is the driving factor that motivates the students to learn English language. $100 \%$ participants see the importance of the foundation courses in English proficiency, which is to prepare them to continue with the cores and specialization courses. The desire to learn English language as an instrumental language to get access to different forms of entertainment and lifestyles is also obvious. 100 percent 
of the participants indicate their motivation to learn English language for the purpose of understanding news, movies, and music in English, as well as using apps and the Internet resources in English. 82 percent respondents indicate their motives to communicate with international friends and colleagues. Only 78 percent indicates the motivation to have good jobs in the future.

The data from the interviews, however, gives a lightly different result as $100 \%$ interviewed participants indicate their motivation to find a good job with their good English competence. $100 \%$ interviewed participants also indicate the high level of intrinsic motivation that pushes them to improve their English language skills. The respondents also express their wish to study well in the later stage of the program. Table 1 summarizes the most important motivations to learn English among the participants.

Table 1. Major motivations for acquiring English language skills

\begin{tabular}{|l|c|c|}
\hline \multicolumn{1}{|c|}{ Motivation } & Number & Percentage \\
\hline $\begin{array}{l}\text { 1. to access to news, movies, music in } \\
\text { English }\end{array}$ & 288 & 100 \\
\hline $\begin{array}{l}\text { 2. to have better travelling experience } \\
\text { abroad }\end{array}$ & 288 & 100 \\
\hline $\begin{array}{l}\text { 3. to be able to continue the cores and } \\
\text { specializations }\end{array}$ & 288 & 100 \\
\hline 4. to have good jobs in the future & 224 & 78 \\
\hline $\begin{array}{l}\text { 5. to work in an international working } \\
\text { environment }\end{array}$ & 219 & 76 \\
\hline $\begin{array}{l}\text { 6. to make good use of IT devices and } \\
\text { the Internet }\end{array}$ & 180 & 62 \\
\hline 7. to satisfy parents' expectations & 160 & 55.5 \\
\hline $\begin{array}{l}\text { 8. to gain higher results/grades in the } \\
\text { middle and final tests }\end{array}$ & 156 & 54 \\
\hline
\end{tabular}

\subsection{Factors Affecting Learning Motivation}

Data from the interviews find out that the main factors that have significant impacts on the learning motivation of the students include the teacher, the course atmosphere, the learning environment, the expectations and supports from students' parents, and the rates of incomes revealed in the job market. These are mainly the extrinsic factors, in which teacher plays the most important role. $100 \%$ respondents comment that teaching methods, assessment procedure, and teacher-student interaction have strong impact on their learning behavior and performance. As being mentioned earlier, professional and caring teachers motivate the students to do well in their study.

The intrinsic factors include student's language competency, student's type of personality and personal interests. 24 interviewed students (66\%) mention their difficulties in learning English due to their lack of vocabulary and competence in communication in English. These difficulties hinder their motivation of learning. Nearly $40 \%$ interviewed students (14 participants) do not gain confidence in communicating in English with foreign lecturers. More than $70 \%$ (25 students) do not have confidence in making presentations in English in front of their teachers and their peers. Instead of making efforts to overcome these obstacles, the students find it difficult to keep up their motivation during the course.

Other causes that interfere the motivation of learning experienced by the respondents come from the distraction of many short-term motivations. These short-term activities include spending time at cafeteria with friends, playing digital games, learning new IT devices, watching K-drama series, earning extra money by doing part-time work, and exploring independent life away from home.

The study also finds out that the respondents highly benefit from studying with international lecturers who enhance their motivation to practice English inside and outside class. Being able to communicate well with foreign lecturers is an authentic test on the student's ability to use English. Regular interaction with international lecturers also fosters the predominant intrinsic motivation among the students, which is the motivation to learn new cultures, language, and people around the world.

\section{Conclusions}

As described above, developing English language competence is the foundational part in the whole curriculum of the English majored undergraduates. It paves the significant way for the students to take on their cores and specialization courses in the later years of their college life. It is, therefore, important for the students to diagnose their own motives of learning from the first years of their study. This study has identified the main factors that significantly affect the motivation to learn English language skills of the participating students. Those intrinsic and extrinsic factors should be either enhanced or eased out so that the students can keep up their positive motivation, enrich their learning experience, and achieve better learning results.

It is worth to highlight that the teacher has a vital role in the student's learning experience. The teacher can place the positive impact on the student's achievement with their appropriate teaching methodology, fair judgement on student work, and adequate counselling time.

The student's confidence in using English is another critical matter that affects the motivation to study among the students, especially the freshman. Student activities on campus and outside campus such as student contests, student clubs, and community work are suggested to be held regularly to give students the opportunity to express themselves and interact socially with one another. English speaking environment on campus is also necessary to help students to improve their English language skill and competence.

The need to extend the number of international students in yearly intakes is increasing, which certainly creates an 
effective learning environment for all students. In brief, student's motivation of learning, either short-term or long-term, certainly continues to change and grow in the course of time. The educational environment which is focused on creating the student's motivation is always of high value.

Further research is suggested to investigate the correlation of student's motivation and learning outcomes and achievement. A longitudinal study on the changes in motivation of students from first year as freshman to the last years as senior is also highly recommended.

\section{Acknowledgments}

This work is funded by Hong Bang International University under grant code GV 2014.

\section{REFERENCES}

[1] Vietnam National University Ho Chi Minh City , "New Trends in Teaching Foreign Languages," in New Trends in Foreign Languages Teaching in Industrial Age 4.0, Ho Chi Minh City, 2018.

[2] H. D. Brown, Principles of Language Learning and Teaching, New York, Pearson Education, 2007.

[3] R. Gardner, "The Scio-educational model of second language acquisition," in The Palgrave Handbook of Motivation for Language Learning, M. Lamb, K. Csizer, A. Henry, S. Ryan, Ed., Switzerland, Palgrave Macmillian, 2019.

[4] J. Harmer, The Practice of English Teaching, England, Longman, 2007.
[5] R. Sprinthall, N. Sprinthall, S. Oja, Educational Psychology. A Developmental Approach, Boston, McGraw-Hill, 1998.

[6] P. Sundqvist, L. Sundqvist, Extramural English in Teaching and Learning - From Theory and Research to Practice, London, Palgrave Macmillan, 2016.

[7] P. M. Lightbrown, N. Spada, "Factors affecting second language learning," in English Language Teaching in Its Social Context, C.N. Cadlin, N. Mercer, Ed., London, Routledge, 2001, pp. 28-44.

[8] E. W. Brewer, N. D. Burgess, "Professor's role in motivating students to attend class," Journal of Industrial Teacher Education, vol. 3, no. 42, pp. 23-47, 2005.

[9] E. L. Deci, R. M. Ryan, Intrinsic Motivation and Self-Determination in Human Behavior, New York, Plenum, 1985.

[10] G. Richter, D. R. Raban, S. Rafaeli, "Studying gamification: the effect of rewards and incentives on motivation," in Gamification in Education and Business, Switzerland, Springer International Publishing, 2015, pp. 21-46.

[11] R. Mitchell, F. Myles, "Second Language Learning : Key Concepts and Issues," in English Language Teaching in Its Social Context, L C.N. Cadlin, N. Mercer, Ed., London, Routledge, 2001, pp. 11-27.

[12] A. Mirzaei, F. Forouzandeh, "Relationship between intercultural communicative competence and L2 leanring motivation of Iranian EFL learners," Journal of Intercultural Communication Research, vol. 3, no. 42, pp. 300-318, 2013.

[13] L. Tran, "Learners' motivation and identity in the Vietnamese EFL writing classroom," English Teaching: Practice and Critique., vol. 6, no. 1, pp. 151-163, 2007.

[14] J. Archer, B. Truong, "Examining the motivation and achievement of Vietnamese university students as they undertake English classes," in English Tertiary Education in Vietnam, J. Albright, Ed., New York, Routledge, 2019. 